\title{
ENSURING BUSINESS TRANSPARENCY \\ AS THE MOST IMPORTANT ACCOUNTING AND ANALYTICAL FUNCTION IN THE CONTEXT OF THE CORONACRISIS
}

\author{
Roman R. Chugumbaev \\ Moscow State Humanitarian-Economic University, Moscow, Russian Federation
}

\begin{abstract}
Economic entities once again found themselves in the conditions of "new normality", now it is a global coronocrisis. The new complex context of decision-making caused by the pandemic requires that information and analytical support be kept up to date. Therefore, in this article it is proposed to pay attention to the mechanisms of ensuring transparency of business. The study begins with a discussion of the factors that contributed to the increased need for business transparency during the pandemic. At the same time, transparency is considered from the perspective of various stakeholders of the economic entity. The opportunities, benefits and effects that can become available to organizations committed to responsible and transparent functioning are also considered. The author notes the complex positive impact of transparency on the functioning of business as a whole. Further, it is proposed to focus on the problems of internal transparency caused by the peculiarities of the organization of work of employees during the pandemic. Many employees of Russian companies moved their employees to remote operation, which caused some difficulties in monitoring the implementation of business processes. Due to the need for rapid implementation of organizational changes of an innovative nature during the pandemic, the study separately presents the role of transparency in the implementation of transformational changes of the company. The paper also identifies the main areas of transparency activities.
\end{abstract}

Key words: transparency of the business, stakeholder theory, sustainable development, coronacrisis, innovation activities.

Citation. Chugumbaev R.R. Ensuring Business Transparency as the Most Important Accounting and Analytical Function in the Context of the Coronacrisis. Vestnik Volgogradskogo gosudarstvennogo universiteta. Ekonomika [Journal of Volgograd State University. Economics], 2020, vol. 22, no. 4, pp. 88-98. (in Russian). DOI: https://doi.org/10.15688/ek.jvolsu.2020.4.8

УДК 338:33.012.1

ББК 65.290 .2
Дата поступления статьи: 15.10 .2020

Дата принятия статьи: 01.11.2020

\section{ОБЕСПЕЧЕНИЕ ТРАНСПАРЕНТНОСТИ БИЗНЕСА КАК ВАЖНЕЙШАЯ УЧЕТНО-АНАЛИТИЧЕСКАЯ ФУНКЦИЯ В УСЛОВИЯХ КОРОНАКРИЗИСА}

\author{
Роман Рыспекович Чугумбаев \\ Московский государственный гуманитарно-экономический университет, \\ г. Москва, Российская Федерация
}


фекты, которые могут стать доступны организациям, приверженным ответственному и прозрачному функционированию. Автор отмечает комплексное положительное воздействие транспарентности на функционирование бизнеса в целом. Далее предлагается сфокусировать внимание на проблемах внутренней транспарентности, вызванных особенностями организации работы сотрудников в период пандемии. Многие российские компании перевели сотрудников на удаленный режим работы, что вызвало определенные трудности в контроле за выполнением бизнес-процессов. В связи с необходимостью в период пандемии мгновенного внедрения организационных изменений инновационного характера в исследовании отдельно охарактеризована роль транспарентности в осуществлении трансформационных преобразований компании. Кроме того, в работе определяются основные направления деятельности по обеспечению транспарентности.

Ключевые слова: транспарентность бизнеса, теория заинтересованных сторон, устойчивое развитие, коронакризис, инновационная деятельность.

Цитирование. Чугумбаев Р. Р. Обеспечение транспарентности бизнеса как важнейшая учетно-аналитическая функция в условиях коронакризиса // Вестник Волгоградского государственного университета. Экономика. - 2020. - Т. 22, № 4. - C. 88-98. - DOI: https://doi.org/10.15688/ek.jvolsu.2020.4.8

\section{Введение}

Повышенное внимание ученых, профессионалов к вопросам транспарентного функционирования бизнеса в последние годы обычно связывают с глобальными инициативами в сфере устойчивого развития и корпоративной социальной ответственности. Современное общество при активной работе международных институтов сфокусировало внимание макро- и микроэкономических субъектов на проблемах экологии, заботы о будущих поколениях, социальной справедливости и ответственности, развития инклюзивной экономики. В международной деловой практике все более прочно закрепляется культура взаимоотношений экономических субъектов, основанная на высокой степени информационной открытости, обеспечении транспарентности правовой и экономической среды. Цели в области устойчивого развития, совместно принятые государствами - членами ООН, оказали существенное влияние как на содержание, так и на архитектонику стратегии большинства компаний мира.

Приверженность целям устойчивого развития усложняет контекст принятия управленческих решений в организации, поскольку предполагает учет требований более широкого круга заинтересованных сторон. В связи с этим компании, их партнеры, государство, общество для осуществления эффективных с точки зрения устойчивого развития процессов нуждаются в широком обмене информацией. В период пандемии внимание общественности и органов государственного регулирования к решениям бизнеса подчеркивает особую роль концепции социальной ответственности бизнеса.

Успех функционирования и развития экономических субъектов в период пандемии создает новые возможности для того, чтобы проявить социальную ответственность и стать «ближе» к обществу [Palma-Ruiz et al., 2020]. Условия, в которых оказались экономические субъекты, становятся испытанием того, насколько они в реальности привержены принципам устойчивости и социальной ответственности. Отношение руководства к безопасности персонала на рабочих местах, переход на удаленную работу, обеспечение средствами индивидуальной защиты и другое может многое сказать о реальной заботе компании о работниках. Условия функционирования бизнеса в период пандемии COVID-19 открыли компаниям возможности для активного участия в реализации своих программ корпоративной социальной ответственности и приверженности широко известным целям устойчивого развития. Должное внимание и забота компании о персонале, потребителях, поставщиках, обществе и всем ключевым стейкхолдерам может надолго сохраниться в памяти социума и стать надежным социальным капиталом, обеспечивающим долгосрочную устойчивость бизнеса.

Очевидно, что пандемия создает угрозы для бизнеса. Современные компании внимательно следят за информацией об изменениях в ключевых областях своей внешней деловой среды и стремятся устранять непосредственные и критические угрозы, возника- 
ющие в результате пандемии. В результате пандемии COVID-19 менеджмент организаций сталкивается со значительной неопределенностью внешней среды и испытывает дефицит достоверной информации, позволяющей адекватно реагировать на преобразования в среде функционирования. В период пандемии изменения условий работы организаций отличаются своей скоростью, что усиливает требования к оперативности поступления экономической информации. По этой причине данное исследование направлено на изучение феномена транспарентности бизнеса в условиях преодоления последствий кризиса, вызванных пандемией COVID-19.

\section{Методы}

Данное исследование начинается с определения факторов, повлиявших на усиление потребности в транспарентности бизнеса в период пандемии. При этом транспарентность рассматривается с позиции различных заинтересованных сторон экономического субъекта. Кроме того, анализируются возможности, выгоды и эффекты, которые могут стать доступны организациям, стремящимся к ответственному и прозрачному функционированию. Далее предлагается сфокусировать внимание на проблемах внутренней транспарентности, вызванных особенностями организации работы сотрудников в период пандемии. Многие российские компании перевели сотрудников на удаленный режим работы, что вызвало определенные трудности контроля выполнения бизнес-процессов. В связи с необходимостью в период пандемии скорого внедрения организационных изменений инновационного характера в исследовании отдельно представлена роль транспарентности в осуществлении трансформационных преобразований компании. Кроме того, в работе предложены направления деятельности по обеспечению транспарентного функционирования организации:

1. Усиление потребности в транспарентности бизнеса в период коронакризи$c a$. Неспокойные времена, такие как период пандемии, влекут за собой множество серьезных преобразований как во внутренней, так и во внешней сфере окружающей среды, при- чем такие изменения иногда сопряжены с разрушением прежних связей, отношений или иных элементов. Необходимо, чтобы российские компании нашли оптимальный путь адаптации к новым условиям работы.

На наш взгляд, транспарентное функционирование экономических субъектов в настоящее время важнее, чем когда-либо. Данный тезис объясняется тем, что прозрачная работа во многом позволяет обеспечить доверие и прочные взаимосвязи с ключевыми заинтересованными сторонами бизнеса. Доверие между участниками экономических процессов в новых кризисных условиях чаще всего снижается. Возникают новые опасения, малопредсказуемость поведения партнеров, неопределенность правил и норм, то есть все то, что называют «новой реальностью».

Острая фаза пандемии в России показала, что бизнес и государство в такие времена нуждаются в объединении усилий для обеспечения социально-экономической устойчивости [Buyanova et al., 2020]. Взаимная прозрачность выступает необходимым условием для такого сближения. Государство должно выявлять наиболее пострадавшие области экономической активности для того, чтобы своевременно принять меры преодоления тяжелых последствий пандемии, а также реализовывать адекватные способы поддержки экономических субъектов. Взаимная прозрачность государства и бизнеса способствует более оперативному осуществлению таких действий и минимизации социально-экономического ущерба кризиса.

Не менее важна прозрачность деловых намерений и финансового состояния экономических субъектов во взаимоотношениях с банками, которые также придерживаются более осторожной политики, более внимательны к заемщикам. Многие из последних оказались в трудном финансовом положении, что вынудило их обращаться за реструктуризацией кредитов. Кроме того, многие крупные банки также проявляют готовность к реализации мер поддержки пострадавших клиентов, в том числе и корпоративных. Прозрачность и предсказуемость корпоративных клиентов позволяет банкам своевременно принимать меры, предлагать новые более выгодные в трудный период предложения. 
В стабильные времена экономические субъекты обычно мотивированы к установлению надежных отношений с поставщиками и клиентами, которые обеспечивают повышение операционной эффективности и прибыльности. Однако во время пандемии возникают новые проблемы и задачи, которые сосредоточены не только на получении операционных экономических выгод. Это задачи гуманитарного характера, когда мотивация поведения экономического субъекта становится менее очевидной и предсказуемой. Во время пандемии долгосрочные партнерские отношения при деструктивных изменениях бизнес-среды нуждаются в решениях менеджеров, адекватных новым условиям. Возможно, они могут привести к разрушению прежних связей и отношений для того, чтобы использовать возможности установления новых. Это объясняется тем, что такие взаимоотношения (возможно, новые партнеры лучше подготовлены) способны помочь компании удовлетворить как неотложные краткосрочные потребности, так и открыть новые перспективы долгосрочного характера. Неблагоприятные, быстро меняющиеся условия бизнес-среды во время пандемии могут стать и катализатором для установления настоящего делового партнерства. Источник доверия находится в признании компанией надежности и порядочности своего партнера по операционному взаимодействию.

Транспарентность организации способна продемонстрировать партнерам свою надежность и ответственное отношение. Компания может доверять поставщику, если она верит, что он обладает способностью действовать эффективно и надежно и учитывает интересы покупателя при принятии мер в кризисных условиях. Партнеры должны демонстрировать то, что они ценят отношения и испытывают обязательство друг перед другом предоставлять значимую информацию для принятия эффективных решений. Нужно понимать, что многие поставщики могут использовать коронакризис как предлог для того, чтобы отказаться от взятых на себя обязательств в докризисный период. В связи с этим регулярный обмен информацией партнеров в период пандемии способен существенно сократить потери и показать перспективные направления развития взаимоотношений.
Сотрудники компании также нуждаются в информации о влиянии кризиса на экономику организации. В связи с этим последняя должна усилить информационный обмен внутри компании для того, чтобы снизить уровень паники, стресса и эмоционального характера поведения персонала, вызванный угрозой его финансовому положению, социальному статусу. Некоторые сотрудники в отсутствии необходимой прозрачности излишне оптимистично настроены, что мешает адекватному восприятию ситуации и принятию решений. В связи с этим в период коронакризиса необходимо регулярно обеспечивать персонал достаточно конкретной, доступной, честной информацией, исключающей возможные домыслы, искажения, слухи, преувеличения и т. д.

Как видно, в транспарентности бизнеса нуждаются все перечисленные заинтересованные стороны, а также и другие, в том числе настоящие владельцы бизнеса и потенциальные инвесторы, местные сообщества, общественность в целом и т. д. В период высокой неопределенности, турбулентности бизнессреды все участники социально-экономических процессов нуждаются в надежной, понятной и своевременной информации.

2. Эффекты и возможности бизнеса в период пандемии. Понимание экономических последствий транспарентной информационной среды компании является актуальной темой научных исследований по бухгалтерскому учету в последние годы [Рожнова и др., 2013]. Предлагаем рассмотреть некоторые положительные эффекты от транспарентного функционирования организаций в период пандемии.

Так, подотчетность, как одно из проявлений транспарентности компании, состоит в обеспечении информацией заинтересованных сторон и демонстрации высокого этического уровня бизнеса [Schnackenberg et al., 2016]. Это позволяет сохранить достигнутый уровень доверительных взаимоотношений с ними, а может даже и повысить его. Сокрытие информации, особенно во время ее острой необходимости, как в период коронакризиса, понимается обществом и партнерами как неэтичное отношение и серьезно подрывает доверие. Кроме того, как показывают некоторые исследования, между уровнем деловой этики и 
его финансово-экономическими показателями существует значительная корреляция.

Транспарентное функционирование компании в такой сложный период существенно снижает вероятность того, что надзорные органы, представители органов государственной власти без уведомления будут инициировать внеплановые контрольно-ревизионные мероприятия. В период пандемии такие меры проводятся гораздо чаще обычного, что, конечно, может быть обременительным для организаций, когда помимо этого возникает множество других сложных проблем, требующих внимания. При этом часто контрольные органы проводят внеплановые проверки, реагируя на информацию из внешних источников, например, различных жалоб или сведений, распространяемых в социальных сетях. Очевидно, что такие проблемы минимизируются при транспарентном поведении организации.

Транспарентые компании отличаются высокой степенью вовлеченности ключевых заинтересованных сторон компании в процессы принятия эффективных и сбалансированных решений, что так необходимо бизнесу в период пандемии. Кроме того, при таком подходе заинтересованные стороны чувствуют собственное участие как в успехах, так и в неудачах инициатив компании. В связи с этим в период пандемии ошибки транспарентных компаний в меньшей степени разрушительны. Организация в таких случаях пользуется поддержкой и доверием со стороны заинтересованных сторон.

Прозрачность также сокращает или даже полностью исключает действия, состоящие в злоупотреблении и преследовании корыстных интересов в связи с хаосом и неопределенностью, вызванными пандемическими последствиями и паническими настроениями в обществе. Очевидно, что в период кризиса есть достаточные предпосылки еще большей теневизации деятельности некоторых компаний, а также использованию панических настроений в обществе и повышенной степени неопределенности, турбулентности контекста экономики в спекуляциях и других злоупотреблений, открывающих большие возможности для краткосрочных выгод. Однако следует помнить, что последующее вскрытие фактов корыстных неэтичных дей- ствий, публичный скандал могут молниеносно разрушить деловые связи, репутацию компании и поставить под сомнение целесообразность ее дальнейшего существования. Функция бухгалтерской службы обеспечить минимизацию таких негативных для бизнеса и общества злоупотреблений. Транспарентность является одним из эффективных механизмов реализации данной задачи.

Транспарентность обеспечивает аутентичность сведений об организации, в то время как в период пандемии высока доля фейковой информации в медиапространстве. Следует понимать, что современная компания существует в открытом информационном пространстве и с каждым годом будет все сложнее скрыть факты внутренней жизни компании. Информационная прозрачность является одной из характеристик современного гражданского общества, а развитие информационных технологий обеспечивает мгновенное распространение информации. Если компания не будет раскрывать сведения, представляющие интерес для широкой аудитории, то за нее это могут сделать другие. Открытость и прозрачность функционирования организации минимизируют последствия «информационной атаки» со стороны конкурентов и других субъектов распространения негативной информации о компании.

3. Внутренняя транспарентность бизнеса в период пандемии. Наряду с внешней организационной траспарентностью некоторые исследователи выделяют внутреннюю [Рожнова и др., 2017]. При этом предполагают, что внутренняя прозрачность ориентирована на равную информированность менеджмента компании различного звена о ее текущих и стратегических целях, а также топ-менеджмента и собственников бизнеса. В ходе аназиза внутренней транспарентности приходим к выводу, что менеджмент должен обмениваться информацией, чтобы обеспечить всю систему транспарентности предприятия [Рожнова и др., 2017]. Разумеется, в период пандемии, когда возникает много новых задач, требующих эффективных управленческих решений, менеджмент обязан работать сообща и прозрачно, а новая релевантная информация должна поступать немедленно. В данном исследовании предлагается обратить внимание 
на внутреннюю транспарентность в связи с новыми способами организации работы персонала компании.

Как известно, в период пандемии для того, чтобы обеспечить непрерывность бизнес-процессов, компании в срочном порядке осуществляли перевод сотрудников на дистанционную работу. Ускоренный переход на дистанционный менеджмент, удаленную работу во время пандемии и после также требует обеспечить транспарентность бизнес-процессов, осуществляемых в режиме онлайн. Такая внутренняя информационная прозрачность становится необходимым условием скоординированного и эффективного функционирования бизнеса. Новизна такой организации работы сопряжена с отсутствием правового обеспечения в российских компаниях. Так, только с 1 января 2021 г. вступает в силу Федеральный закон от 08.12.2020 № 407-Ф3 «О внесении изменений в Трудовой кодекс Российской Федерации в части регулирования дистанционной (удаленной) работы и временного перевода работника на дистанционную (удаленную) работу по инициативе работодателя в исключительных случаях».

В условиях удаленной работы сотрудники лишены четкой физической границы между досугом и работой, когда гостиная одновременно является офисом. Практика показывает, что такая гибкость со стороны работодателя требует взамен от работников доступности не только в пределах рабочего графика. Современные цифровые технологии позволяют организовать круглосуточный контроль за деятельностью сотрудника. Очевидно, что задача работодателя - не довести дело до чрезмерного надзора, поскольку в этом случае есть вероятность потери лояльности работников. Так, важна взаимная прозрачность. Работодатель должен довести до сотрудника, в какой мере он использует возможности удаленного наблюдения за его действиями, а сотрудник со своей стороны - предоставить работодателю прозрачную информацию о выполнении бизнес-процессов.

При отсутствии транпарентности удаленного контроля за работой возможны злоупотребления ситуацией как с одной, так и с другой стороны. Так, работодатели могут найти оправдания для такого приема получения ин- формации, как фишинг, когда осуществляется несанкционированный доступ к логинам, паролям и другим данным на домашних компьютерах. Конечно, такие методы несут большие риски доверию со стороны реальных и потенциальных сотрудников, как и риски репутации компании. Инновационные способы повышения прозрачности сбора данных могут быть реализованы с помощью визуальных моделей, показывающих, куда идут данные и для чего используются. Осуществление контроля выполнения бизнес-процессов должно быть прозрачным и понятным как для сотрудников, так и для руководителей. Здесь высока роль бухгалтеров, способных обеспечить внутреннюю транспарентность компании.

4. Активизация инновациионной деятельности в период пандемии. Как уже отмечалось, в период пандемии все мы столкнулись с переменами, изменением способов ведения дел. Все организации, в том числе и субъекты бизнеса, стараются инициировать и реализовать различные по сложности изменения, чтобы решить существующие проблемы. В период пандемии резко возрастает уровень неопределенности, в то время как прозрачное, понятное и ответственное поведение высоко востребовано и значимо. Изменения в новом контексте функционирования бизнеса чаще всего носят инновационный характер.

Инновационные решения по изменению (адаптации) организации в случае их успешного внедрения позволяют как минимизировать экономические потери, так и использовать новые возможности для более эффективной работы. Однако инновации связаны с рисками, особенно если высока степень новизны разрабатываемых и внедряемых решений. Непосредственные и косвенные участники сталкиваются с вопросами и сомнениями относительно инноваций, испытывают потребность получения как можно большего объема информации и занимаются поиском дополнительных деталей, позволяющих оценить перспективность новых идей. Это значит, что инновационная деятельность бизнеса влияет на потребности в транспарентности широкого круга заинтересованных сторон.

Инновации организационного характера в отличие от инвестиций в основной капитал требуют более длительного времени и связа- 
ны в большей мере с рисками различного характера. Исследования и инновационные разработки обычно недостаточно инвестируются из-за внутренних управленческих стимулов, а также из-за ограниченности внешних финансовых ресурсов. Мы считаем, что при достаточно высоком качестве информационно-аналитического обеспечения процесса разработки и внедрения инноваций можно преодолеть проблему недостаточного инвестирования в инновационные проекты.

Практика показывает, что капитальные инвестиции на расширение бизнеса более привлекательны по сравнению с инвестициями в инновационные разработки [Методология анализа ..., 2010]. Одной из причин является то, что инвестиции в основной капитал обеспечивают более доступное внешнее финансирование (кредиты в банках, финансовые лизинги и др.). Кредиторы и инвесторы в таких случаях имеют примерные ожидания эффективности финансируемых активов. При этом объекты таких инвестиций чаще всего могут выступить обеспечением исполнения обязательств и тем самым минимизировать финансовые риски. В сложной малопредсказуемой среде у менеджеров, не склонных к риску, появляется естественный стимул отказаться от создания и приумножения нематериальных активов, инвестиций в инновационные разработки, поскольку это связано с более высоким риском, чем инвестиции в основной капитал.

Другим препятствием инновационной деятельности могут стать сами менеджеры компании. Они понимают, что несут полную ответственность и рискуют своей карьерой, если инновации потерпят неудачу по причинам и обстоятельствам, которые не всегда зависят от качества выполнения обязанностей на рабочих местах. В таком случае обеспечение транспарентности инновационной деятельности способно защитить менеджеров от неоправданных карьерных рисков, предоставив заинтересованным сторонам убедительную и понятную информацию об обстоятельствах проведения исследований, разработок, испытания и внедрения результатов инновационной работы. Такое транспарентное информационное обеспечение позволит отфильтровать реальные просчеты ответственных лиц от ма- локонтролируемых внешних рисков, часто возникающих и ограничивающих эффективность инноваций. С другой стороны, если компания, реализуя инновацию, сталкивается с неудачей, менеджеры к этому могут относиться как к разовому событию, в последствиях которого следует спокойно разобраться, возможно, даже скрыть эту неприятность от заинтересованных сторон. Такой подход не позволяет в достаточной степени понять сущностные причины неудачи, внимательно посмотреть на ретроспективу, признать недостатки в собственной работе и делает компанию уязвимой для дальнейших неудач в инновационной деятельности. Кроме того, заметим, что менеджмент, ответственный за инновации, относится к высшему звену, а такого уровня руководство в редких случаях склонно признавать свои ошибки [Edmondson, 2020]. Культура лидерства, которая обычно является одним из элементов системы мотивации персонала компании [Naile et al., 2014], также может препятствовать признанию ошибок.

Ответственность и транспарентность инновационной деятельности стимулирует руководство перед лицом серьезных проблем более решительно инициировать устранение ущерба, восстановить общественное доверие и предпринять адекватные меры по недопущению повторных просчетов. События, приведшие к неудаче, могут быть неподконтрольными руководству, но то, как они реагируют на это, является важнейшей характеристикой привлекательности инновационной деятельности для ключевых заинтересованных сторон. Как уже отмечалось, транспарентность создает эффект вовлеченности заинтересованных сторон, которые, обладая прозрачной информацией о ходе реализации проекта, чувствовали себя сопричастными, что обеспечивает некоторую лояльность к неудачам.

Несмотря на то что инновационная эффективность имеет жизненно важное значение в период кризиса, менеджеры компаний сталкиваются с серьезными проблемами при определении приоритетов в выборе инновационных проектов. Во время реализации инновационной деятельности некоторые менеджеры могут злоупотреблять собственным положением и извлекать частную выгоду от капитала, сформированного на инновационные 
цели. На этот счет есть достаточный арсенал манипуляций, который можно встретить в практике современного менеджмента. Транспарентность инновационной деятельности за счет предоставления достоверной экономической информации дисциплинирует менеджеров, минимизирует или даже исключает возможность манипуляций и злоупотреблений, а также позволяет им лучше выявлять ценности и эффекты перспективных инновационных проектов. Транспарентность позволит сконцентрировать усилия менеджеров на поиске наиболее эффективного использования капитала, предназначенного для инновационного развития. Понимая, что информация об обоснованности затраченных на проект ресурсов нуждается в тщательной подготовке для предоставления ключевым стейкхолдерам и должна убедить их в наиболее эффективном использовании капитала, менеджеры будут еще более тщательно анализировать принимаемые решения. Это указывает на положительную связь между прозрачностью и инновационной эффективностью.

Однако есть и негативное воздействие транспарентности, когда она влияет на снижение эффективности инновационной деятельности. Речь о том, что информация о деталях инновационной деятельности, которую раскрывает компания, может попасть и к конкурентам. Такие утечки приведут к потере конкурентоспособности, поскольку она формируется во многом за счет инновационной деятельности. На наш взгляд, в условиях коронакризиса экономические субъекты все в меньшей степени конкурируют за счет сокрытия инновационных технологий и бизнес-моделей, успех зависит от скорости и эффективности внедрения инновационных решений. В связи с этим вместо того, чтобы стремиться изолировать конкурентов и всех остальных внешних заинтересованных сторон от представляющей коммерческую тайну информации, предлагаем сфокусировать внимание на положительном влиянии ответственной и прозрачной инновационной деятельности на ее эффективность.

5. Направления работы по обеспечению транспарентности в условиях коронакризиса. Для обеспечения транспарентности бизнеса на систематической основе дол- жна быть организована работа в нескольких направлениях, в которых отмечается существенный объем применения аналитических процедур.

Так, российские исследователи отмечают, что транспарентность связана с совокупностью последовательных действий, формирующих информацию для полного и адекватного представления любых заинтересованных сторон о ключевых аспектах деятельности компании. На наш взгляд, в условиях коронакризиса можно выделить следующие основные направления систематической работы по обеспечению транспарентности:

- тщательный учет и контроль состава и требований заинтересованных сторон;

- обеспечение доступной и адекватной информации для заинтересованных сторон на основе аналитически обработанных данных учетной системы организации;

- контроль уровня качества сведений, подготовленных для заинтересованных сторон;

- обеспечение комплаенс-контроля информации, подлежащей раскрытию;

- осуществление работы по передаче информации до ее потребителей с помощью СМИ и информационно-коммуникативными средствами.

Наибольшее непосредственное влияние вспышка COVID-19 оказывает на людей, а для бизнеса люди - это и стейкхолдеры. Осуществление тщательного учета и контроля состава и требований заинтересованных сторон - важнейшая работа в период коронакризиса, поскольку компания, как уже отмечалось, может поменять состав ключевых заинтересованных сторон, требования которых также претерпевают серьезные трансформации. В период коронакризиса относительно безразличные группы заинтересованных сторон могут оказать прямое влияние на функционирование организации. Так, например, Роспотребнадзор в этот период усилил свою активность, и требования данного ведомства нельзя упустить из внимания.

В период пандемии «резкие» решения стейкхолдеров не всегда учитывают интересы бизнеса, а иногда создают проблемы, на которые требуется также оперативно реагировать. При этом мониторинг как внутренних, 
так и внешних элементов бизнес-среды необходимо проводить в онлайн-режиме, применяя современные информационно-коммуникативные инструменты.

Так, некоторые исследования подтверждают, что пандемия привела к изменению поведение потребителей [Kim, 2020], которые усилили поиск дифференцированного варианта предложения, стремясь к большему разнообразию продукта. Сам характер организации взаимодействия с клиентами изменился. Следует учитывать меняющиеся потребности клиентов в период особого режима и ограничений.

Другой ключевой стейкхолдер любой компании - это ее персонал. В течение периода пандемии компания должна не упустить возможности выйти на новый уровень доверительных отношений с персоналом, требования которых противоречивы в силу общей неопределенности настоящего и будущего.

Поставщики и подрядчики в новых условиях могут, как и все, изменить требования, приоритеты и т. п., и поэтому следует очень внимательно контролировать цепочки поставок и находиться в контакте с ними. Поскольку функционирование современной компании ориентировано на удовлетворение требований широкого круга заинтересованных сторон, очень важно обеспечить их информацией, позволяющей дать адекватную оценку альтернативным решениям. В связи с этим следует внимательно относиться к составу ключевых заинтересованных сторон, а также обеспечить систематический мониторинг требований. Последствия ограничительных мер во время пандемии существенно меняют контекст функционирования и развития бизнеса, поэтому необходим своевременный учет изменений в требованиях заинтересованных сторон.

Одним из важнейших требований транспарентности информации является то, что она позволяет дать адекватную оценку ситуации для заинтересованных сторон [Rawlins, 2008]. Аналитическая обработка сведений, поступающих из учетной системы, является крайне необходимой, поскольку предоставление информации и обеспечение ее транспарентности - не одно и то же. Транспарентной является информация, доступная для широкого кру- га пользователей, среди которых могут оказаться и недостаточно квалифицированные для понимания финансовой и нефинансовой отчетности, подлежащей раскрытию. Компании следует самостоятельно провести аналитические процедуры в отношении раскрываемой информации и предоставить ключевым заинтересованным сторонам системно организованную и понятную информацию, в которой можно быстро и легко выделить релевантную часть для принятия решений. От того, какие методы и приемы анализа применялись, зависит уровень транспарентности бизнеса.

Необходимо также иметь в виду, что в случае использования публичной отчетности компании заинтересованными сторонами для самостоятельной оценки ситуации, они должны убедится в достоверности и надежности выводов и оценок аналитически обработанной информации. Такое условие существенно усложняет работу бухгалтера-аналитика и требует от него высокой квалификации.

Для того чтобы результаты анализа подтверждались при его проведении заинтересованными сторонами, следует осуществлять контроль качества аналитически обработанной информации до публикации сведений (имеет превентивный характер) и после него (основан на сравнении ожидаемых результатов транспарентности и достигнутых). Для этого необходимо осуществлять оценку выполнения требований заинтересованных сторон по транспарентности на основе мониторинга.

Обеспечение комплаенс-контроля информации, подлежащей раскрытию, также имеет контрольный характер. Так, в одном из исследований подчеркивается особая роль безопасности публикуемых данных. При этом автор предлагает группировать информацию, подлежащую обязательному раскрытию, необязательную к раскрытию и закрытую (конфиденциальная). Очевидно, раскрытие информации, кроме выгод, несет также и риски как для самой компании, так и для заинтересованных сторон, имеющих к ней отношение. Недопустимо, чтобы при выполнении требований одних заинтересованных сторон, был нанесен серьезный ущерб другим.

Осуществление работы по доведению информации до потребителей с помощью СМИ и информационно-коммуникативными сред- 
ствами - это важное направление по обеспечению транспарентности, требующее существенных усилий. В настоящее время такая деятельность может быть связана с ведением сайта компании, формированием корпоративных СМИ, работой с внешними СМИ, участием в рейтингах, представлением в соцсетях и т. д.

\section{Заключение}

Проведенное исследование позволяет отметить усиление потребности в транспарентности бизнеса всех стейкхолдеров в период коронакризиса, высокой неопределенности, турбулентности бизнес-среды, когда все участники социально-экономических процессов нуждаются в надежной, понятной и своевременной информации. Транспарентное функционирование в период пандемии позволяет получить доверие заинтересованных сторон, снижает вероятность внеплановых контрольно-ревизионных мероприятий со стороны надзорных органов, обеспечивает высокую степень вовлеченности в процессы принятия решений ключевых заинтересованных сторон компании, исключает злоупотребления в период хаоса и неопределенности, обеспечивает аутентичность сведений об организации.

Ускоренный переход на дистанционный менеджмент, удаленную работу в период пандемии и после нее требует обеспечить внутреннюю транспарентность бизнес-процессов, осуществляемых в режиме онлайн. При отсутствии транспарентности удаленного контроля и работы возможны злоупотребления ситуацией как с одной, так и с другой стороны. Кроме того, исследование демонстрирует, что транспарентность способствует эффективности инноваций в преобразовании инвестиций в интеллектуальный капитал, что является мотивирующим фактором для руководителей. Инновации в период кризиса - важнейший источник повышения устойчивости бизнеса.

Кроме того, хотелось бы подчеркнуть, что транспарентность сама по себе способствует созданию ценности для заинтересованных сторон, что повышает доверие и привлекательность транспарентной инновационной деятельности, в том числе и для инвесторов.
В исследовании выделено пять различных направлений работ по транспарентности организации, в которых отмечается существенный объем применения аналитических процедур и других видов работ, требующих высокой квалификации учетных специалистов. При этом важно обеспечить комплаенсконтроль сведений, подлежащих раскрытию.

Таким образом, обеспечение транспарентности экономических субъектов в период преодоления разрушительных последствий пандемии является важнейшим комплексом учетно-аналитических работ, требующих высокой квалификации.

\section{СПИСОК ЛИТЕРАТУРЫ}

Методология анализа результатов операционной и финансово-инвестиционной деятельности хозяйствующих субъектов : монография / В. И. Бариленко [и др.]. - М. : Финансовая академия при Правительстве Российской Федерации, 2010. - 459 с.

Рожнова, О. В.Транспарентность как приоритетное направление повышения качества отчетности предприятий / О. В. Рожнова, В. В. Марков, В. М. Игумнов // Известия Московского государственного технического университета МАМИ. - 2013. - Т. 5, № 1 (15). - С. 80-84.

Рожнова, О. В. Формирование транспарентной финансовой отчетности предприятия : монография / О. В. Рожнова, В. М. Игумнов. - М. : РУСАЙНС, 2017. - 132 c.

Buyanova, M. E. Industrial Revolution 4.0: Tendencies and Risks of Social and Economic Changes in the Regions of Russia / M. E. Buyanova, N. A. Mikhaylova // Lecture Notes in Networks and Systems. - 2020. - Vol. 110. - P. 95-102.

Edmondson, A. C. Strategies for Learning from Failure / A. C. Edmondson // Harvard Business Review. 2011. - Vol. 89, № 4.

Kim, J. Impact of the Perceived Threat of COVID-19 on Variety-Seeking / J. Kim //Australasian Marketing Journal. - 2020. - Vol. 28, № 3. - P. 108-116.

Koivisto, I. I. The Anatomy of Transparency: The Concept and its Multifarious Implications / I. I. Koivisto//EUI Working Papers MWP. - 2016. - № 9 .

Naile, I. The Role of Leadership in Employee Motivation / I. Naile, J. M. Selesho// Mediterranean Journal of Social Sciences. - 2014. - Vol. 5, № 3. - P. 175-182.

Palma-Ruiz, J. M. Socially Responsible Investing as a Competitive Strategy for Trading Companies in Times of Upheaval Amid COVID-19: Evidence 
from Spain / J. M. Palma-Ruiz, J. Castillo-Apraiz, R. Gómez Martínez // International Journal of Financial Studies. - 2020. - Vol. 8, № 3.

Rawlins, B. Give the Emperor a Mirror: Toward Developing a Stakeholder Measurement of Organizational Transparency / B. Rawlins // Journal of Public Relations Research. - 2008. - Vol. 21, № 1. P. 71-99.

Schnackenberg, A. K. Organizational Transparency: A New Perspective on Managing Trust in Organization-Stakeholder Relationships /A. K. Schnackenberg, E. C. Tomlinson// Journal of Management. - 2016. - Vol. 42, № 7. P. $1784-1810$.

\section{REFERENCES}

Barilenko V.I., Melnik M.V., Gerasimova E.B., Korolev O.G., Bulyga R.P., Kuchinsky A.V., Efimova O.V., Berdnikov V.V., Negashev E.V., Gavel O.Yu., Valeev R.R. Metodologiya analiza rezul'tatov operacionnoj $i$ finansovoinvesticionnoj deyatel'nosti hozyajstvuyushchih subyektov: monografiya [Methodology for Analyzing the Results of Operational and Financial and Investment Activities of Economic Entities: Monograph]. Moscow, Finansovaya akademiya pri Pravitelstve Rossiyskoy Federatsii, 2010. 459 p.

Rozhnova O.V., Markov V.V., Igumnov V.M. Transparentnost' kak prioritetnoe napravlenie povysheniya kachestva otchetnosti predpriyatij [Transparency as a Priority Direction for Improving the Quality of Enterprise Reporting]. Izvestiya Moskovskogo gosudarstvennogo tekhnicheskogo universiteta MAMI, 2013, vol. 5, no. 1 (15), pp. 80-84.
Rozhnova O.V., Igumnov V.M. Formirovanie transparentnoj finansovoj otchetnosti predpriyatiya: monografiya [Formation of Transparent Financial Statements of the Enterprise: Monograph]. Moscow, RUSAYNS, 2017. 132 p.

Buyanova M.E., Mikhaylova N.A. Industrial Revolution 4.0: Tendencies and Risks of Social and Economic Changes in the Regions of Russia. Lecture Notes in Networks and Systems, 2020, vol. 110, pp. 95-102.

Edmondson A.C. "Strategies for Learning from Failure". Harvard Business Review, 2011, vol. 89, no. 4.

Kim J. Impact of the Perceived Threat of COVID-19 on Variety-Seeking. Australasian Marketing Journal, 2020, vol. 28, no. 3, pp. 108-116.

Koivisto I.I. The Anatomy of Transparency: The Concept and Its Multifarious Implications. EUI Working Papers MWP, 2016, no. 9.

Naile I., Selesho J.M. The Role of Leadership in Employee Motivation. Mediterranean Journal of Social Sciences, 2014, vol. 5, no. 3, pp. 175-182.

Palma-Ruiz J. M., Castillo-Apraiz J., Gómez Martínez R. Socially Responsible Investing as a Competitive Strategy for Trading Companies in Times of Upheaval Amid COVID-19: Evidence from Spain. International Journal of Financial Studies, 2020, vol. 8, no. 3.

Rawlins B. Give the Emperor a Mirror: Toward Developing a Stakeholder Measurement of Organizational Transparency. Journal of Public Relations Research, 2008, vol. 21, no. 1, pp. 71-99.

Schnackenberg A.K., Tomlinson E.C. Organizational Transparency: A New Perspective on Managing Trust in Organization Stakeholder Relationships. Journal of Management, 2016, vol. 42, no. 7, pp. 1784-1810.

\section{Information About the Author}

Roman R. Chugumbaev, Candidate of Sciences (Economics), Associate Professor, Department of Finance, Accounting and Taxation, Moscow State Humanitarian-Economic University, Losinoostrovskaya St, 49, 107150 Moscow, Russian Federation, romanry@ya.ru, https://orcid.org/0000-0001-6571-3464

\section{Информация об авторе}

Роман Рыспекович Чугумбаев, кандидат экономических наук, доцент кафедры финансов, бухгалтерского учета и налогообложения, Московский государственный гуманитарно-экономический университет, ул. Лосиноостровская, 49, 107150 г. Москва, Российская Федерация, romanry@ya.ru, https://orcid.org/0000-0001-6571-3464 